\section{Cureus}

Received 06/05/2019

Review began 06/10/2019

Review ended 06/11/2019

Published 06/16/2019

\section{(๑) Copyright 2019}

Obasi et al. This is an open access article distributed under the terms of the Creative Commons Attribution License CC-BY 3.0., which permits unrestricted use, distribution, and reproduction in any medium, provided the original author and source are credited.

\title{
Unilateral Perioral, Thumb, and Thenar Numbness Secondary to Acute Thalamic Infarct
}

\author{
Jennifer Obasi ${ }^{1}$, Justin C. Chen ${ }^{2}$, Trenton VandeWater ${ }^{3}$
}

1. Internal Medicine, Medical College of Wisconsin Affiliated Hospitals, Milwaukee, USA 2. Emergency Medicine, Medical College of Wisconsin, Milwaukee, USA 3. Physical Medicine and Rehabilitation, Medical College of Wisconsin, Milwaukee, USA

$\square$ Corresponding author: Jennifer Obasi, jobasi2@gmail.com

Disclosures can be found in Additional Information at the end of the article

\section{Abstract}

Lacunar infarcts are small, deep infarcts that occur in subcortical regions of the brain and can result in pure sensory stroke syndromes, ataxia, and dysarthria. The most common predisposing etiology is small-vessel lipohyalinosis or microatheroma formation usually secondary to diabetes mellitus or systemic hypertension. We report a patient who presented with cheiro-oral syndrome (COS) with left sided perioral, thumb, and thenar numbness after an acute lacunar infarct of the right thalamus.

Categories: Internal Medicine, Neurology

Keywords: numbness, stroke, paresthesia, perioral

\section{Introduction}

Lacunar strokes make up approximately $15 \%-21 \%$ of all strokes [1-2]. These infarcts occur in the basal ganglia (including the thalamus), subcortical white matter and pons, usually affecting a singular penetrating branch of a larger cerebral artery. Blockage of these small arteries typically occurs due to lipohyalinosis and embolic or atheromatous occlusion [3]. Similar to other strokes, chronic hypertension is the most important risk factor [4]. Acute thalamic stroke can present with a variety of sensory and motor deficits based on the topographic area of infarction [5]. Less commonly, acute thalamic stroke can present with cheiro-oral syndrome (COS), characterized by purely sensory deficits in unilateral fingers and ipsilateral perioral region, with its distribution making it easy to miss in the acute setting [6].

\section{Case Presentation}

A 71-year-old man presented to ED with a chief complaint of left-sided numbness. Approximately five hours prior to arrival, the patient developed sudden onset of left-sided perioral, thumb, and thenar numbness. Past medical history was significant for coronary artery disease, type 2 diabetes, chronic kidney disease, hypertension, and clear cell renal cell carcinoma status post nephrectomy (10 years prior). The patient had taken two tablets of baby aspirin prior to arrival. He denied having any deficits prior to onset of symptoms, and denied any changes in vision, speech difficulties, weakness, ataxia, chest pain, palpitations, or shortness of breath. Vitals were notable for hypertension with systolic blood pressures ranging from 150s to 190s. Symptoms resolved spontaneously about 30 min after arrival to the ED and on examination the patient was found to have no residual neurological deficits. The patient denied secondary causes for perioral numbness including hypocalcemia, 


\section{Cureus}

thyroid dysfunction, history of seizures, and/or migraines. Due to complaint of lateralized paresthesias and multiple risk factors for stroke, workup for a potential transient ischemic attack was begun.

Laboratory workup was significant for serum creatinine of $1.28 \mathrm{mg} / \mathrm{dL}$ and glucose of 213 $\mathrm{mg} / \mathrm{dL}$, otherwise basic metabolic panel (BMP) was normal. Thyroid stimulating hormone (TSH), complete blood count (CBC), and coagulation screen were unremarkable. Lipid panel was remarkable for cholesterol of $199 \mathrm{mg} / \mathrm{dL}$, low density lipoprotein (LDL) of $98 \mathrm{mg} / \mathrm{dL}$, triglyceride of $259 \mathrm{mg} / \mathrm{dL}$, and high density lipoprotein (HDL) of $49 \mathrm{mg} / \mathrm{dL}$. Glycated hemoglobin was 7.0\%. Initial imaging was done with noncontrast CT of the head which showed age-appropriate involutional changes without acute intracranial hemorrhage (Figure 1).

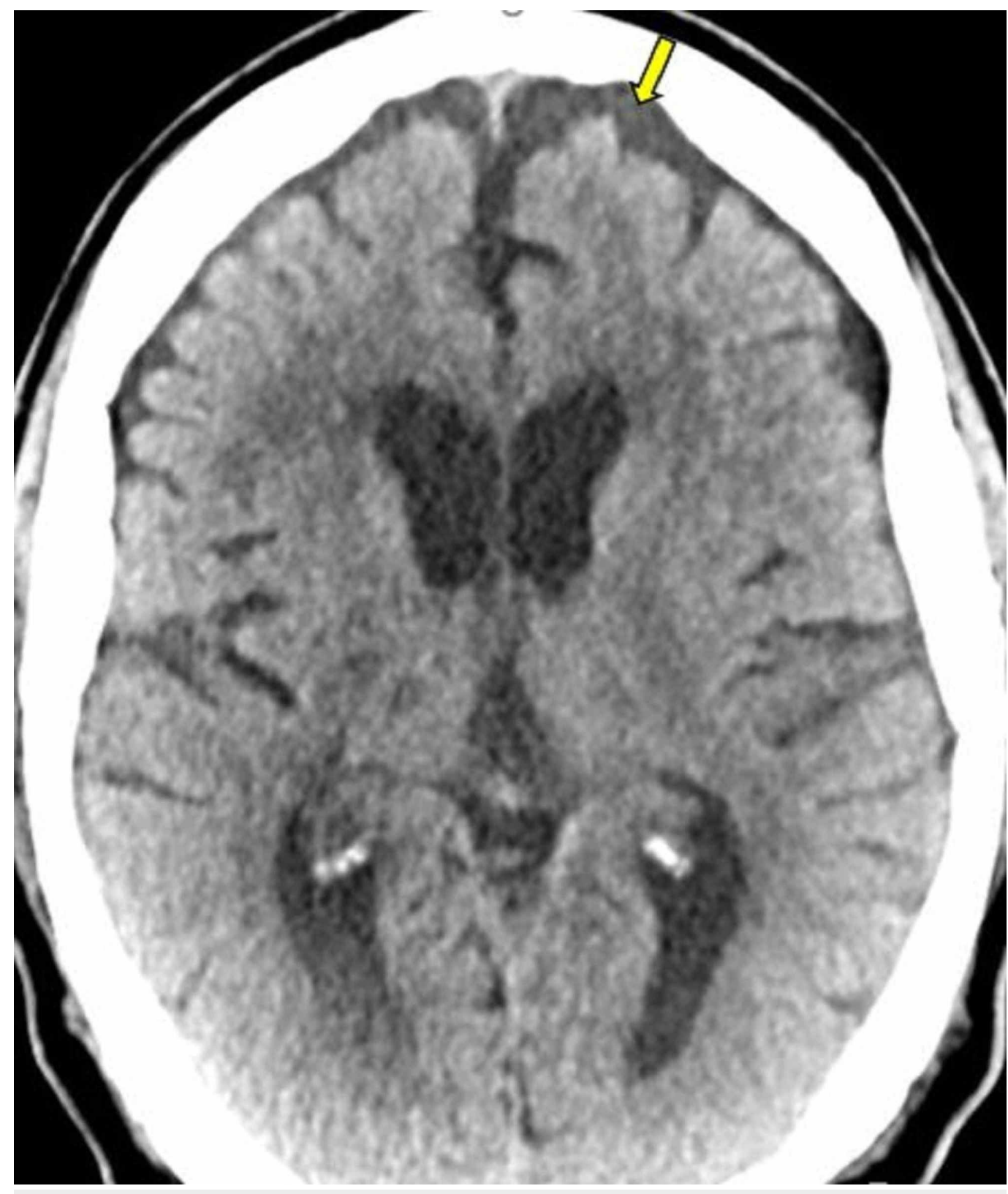

FIGURE 1: CT of the head showing age appropriate involutional changes (yellow arrows). No acute intracranial process. 


\section{Cureus}

Computed tomography angiography (CTA) of the head and neck was unremarkable.

Transthoracic echocardiogram (TTE) did neither reveal a patent foramen ovale nor thrombi.

Electrocardiogram (ECG) was unchanged from prior and revealed normal sinus rhythm.

Follow up imaging was done with MRI of the brain which showed an acute lacunar infarct of the right thalamus and other chronic changes (Figures 2-3).

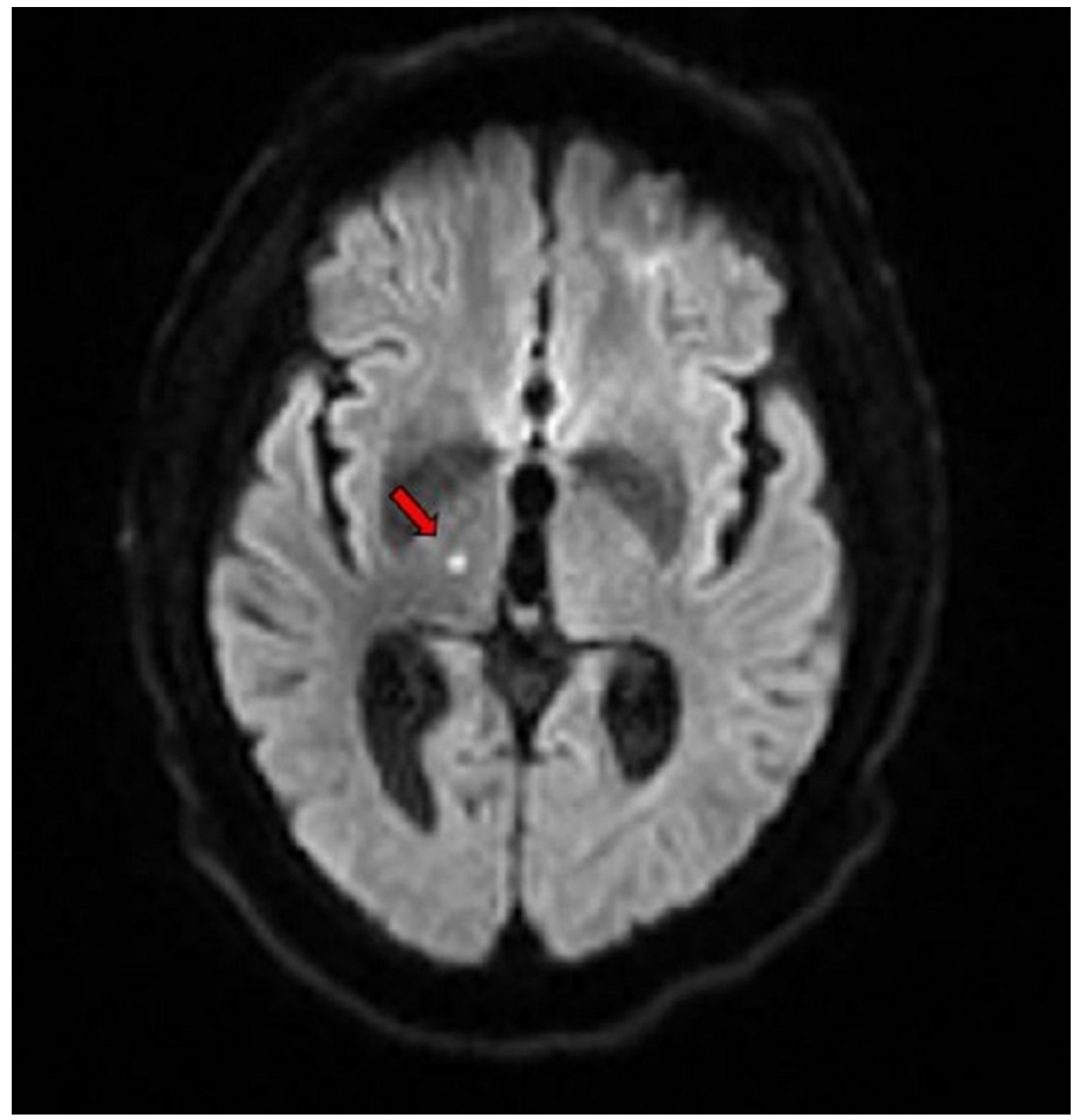

FIGURE 2: MRI of the brain showing punctuate foci of restricted diffusion in the right thalamus (red arrow) consistent with an acute lacunar infarct. 


\section{Cureus}

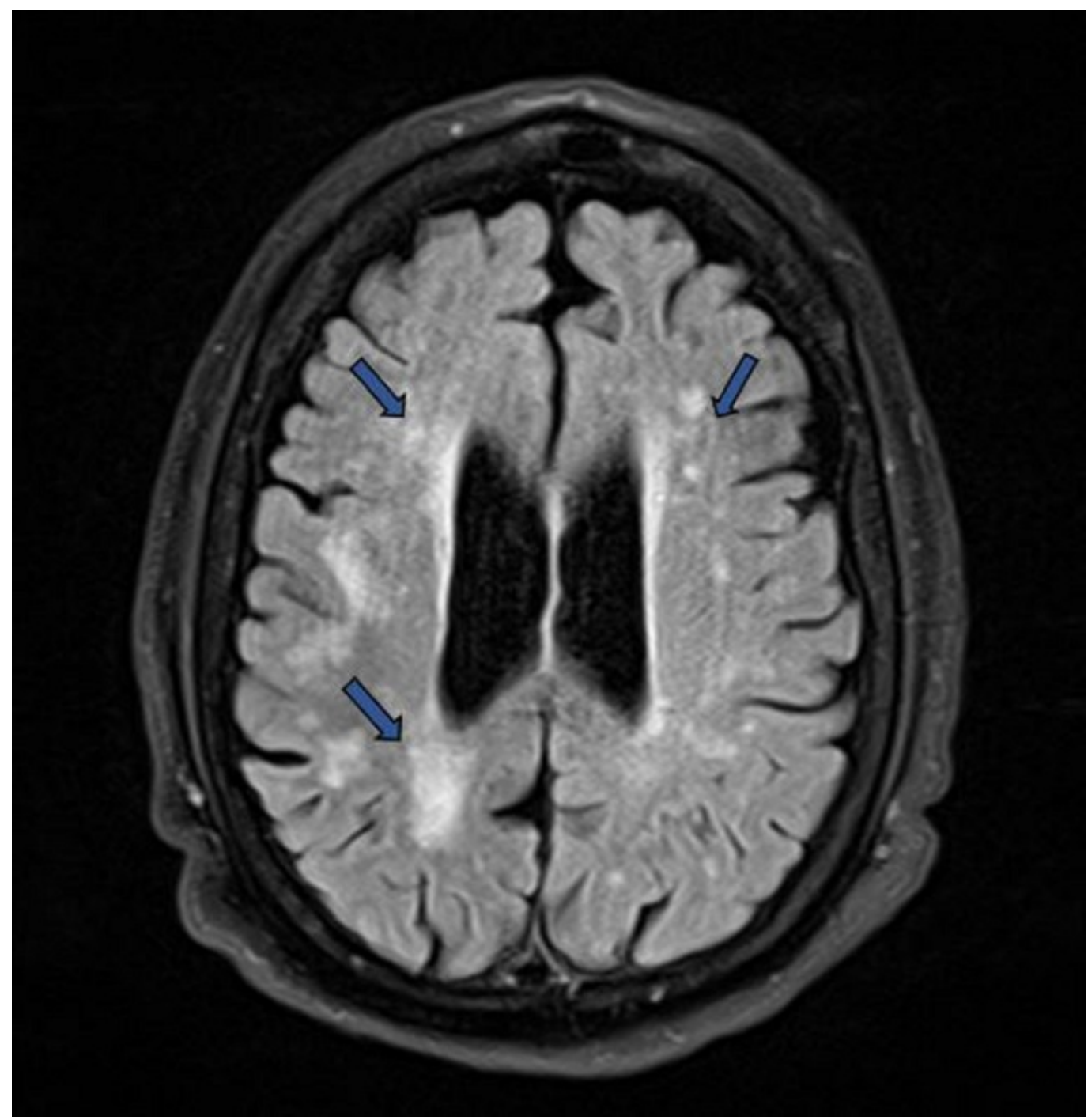

FIGURE 3: MRI of the brain showing multifocal and confluent hyperintense lesions in the periventricular white matter (blue arrows), most likely due to chronic small vessel ischemia.

The patient was diagnosed with an acute right thalamic infarct with findings consistent with COS. He was not a candidate for thrombolytic therapy with intravenous alteplase. He was started on high-intensity statin therapy, and dual antiplatelet therapy (DAPT) with aspirin and clopidogrel for 30 days, with plans to continue clopidogrel monotherapy thereafter. His antihypertensive medication regimen was also optimized, and he was advised to quit smoking.

\section{Discussion}

Cheiro-oral syndrome is an acute stroke syndrome with a variety of sensory impairments based on distribution. Etiologies include ischemia, hemorrhage, tumor, or vascular malformation [7]. Ischemia and hemorrhage are the leading causes [8]. The most common site of infarcts presenting as COS include the pons and thalamus [8]. A prospective study done to delineate the localization and pathogenesis of COS classified four subtypes of COS based on distribution of sensory impairments. Type 1 COS was a sensory impairment limited to the perioral area and homolateral finger(s)/hand in unilaterality. Type 2 COS was a sensory impairment limited to the perioral area and finger(s)/hand in bilaterality. Type 3 COS was a sensory impairment 
limited to the perioral area and finger(s)/hand where one is involved in bilaterality and the other unilaterality. Type 4 COS was a sensory impairment limited to the perioral area and opposite finger(s)/hand, or crossed COS [8]. Diabetes mellitus and hypertension are common risk factors. Noncontrast CT of the head is the first diagnostic imaging study done in patients with suspected acute stroke, but its sensitivity for detecting lacunar infarcts is low. If clinical suspicion is high, this should be followed up with MRI of the brain [9]. Pure sensory strokes, without associated motor deficits are found in up to $18 \%$ of lacunar stroke syndromes [8], although the true prevalence may be underestimated, especially in patients with transient ischemic attack (TIA).

\section{Conclusions}

Hypertension is a common predisposing condition in patients diagnosed with lacunar infarcts as was evident in the patient presented who had a longstanding history of poorly controlled hypertension. The patient also had a history of diabetes and 50 pack-year smoking history which also increased his risk for cerebrovascular disease.

\section{Additional Information}

\section{Disclosures}

Human subjects: Consent was obtained by all participants in this study. Conflicts of interest: In compliance with the ICMJE uniform disclosure form, all authors declare the following: Payment/services info: All authors have declared that no financial support was received from any organization for the submitted work. Financial relationships: All authors have declared that they have no financial relationships at present or within the previous three years with any organizations that might have an interest in the submitted work. Other relationships: All authors have declared that there are no other relationships or activities that could appear to have influenced the submitted work.

\section{References}

1. Sacco S, Marini C, Totaro R, et al.: A population-based study of the incidence and prognosis of lacunar stroke. Neurology. 2006, 9:1335-1338. 10.1212/01.wnl.0000210457.89798.0e

2. Bamford J, Sandercock P, Jones L, et al.: The natural history of lacunar infarction: the Oxfordshire Community Stroke Project. Stroke. 1987, 18:545-551. 10.1161/01.STR.18.3.545

3. Fisher CM: Lacunar strokes and infarcts: a review. Neurology. 1982, 32:871. 10.1212/wnl.32.8.871

4. Altmann M, Thommessen B, Rønning OM, et al.: Blood pressure differences between patients with lacunar and nonlacunar infarcts. Brain Behav. 2015, 5:00353. 10.1002/brb3.353

5. Steinke W, Sacco RL, Mohr JP, et al.: Thalamic stroke: presentation and prognosis of infarcts and hemorrhages. Arch Neurol. 1992, 1:703-710. 10.1001/archneur.1992.00530310045011

6. Satpute S, Bergquist J, Cole JW: Cheiro-oral syndrome secondary to thalamic infarction: a case report and literature review. Neurologist. 2013, 19:22. 10.1097/NRL.0b013e31827c6c0e

7. Wu YH, Liu KT, Yeh IJ, et al.: Cheiro-oral syndrome caused by thalamus hemorrhage: a case report. Medicine (Baltimore). 2018, 97:e9652. 10.1097/MD.0000000000009652

8. Chen WH: Cheiro-oral syndrome: a clinical analysis and review of literature . Yonsei Med J. 2009, 50:777-783. 10.3349/ymj.2009.50.6.777

9. Hommel M, Besson G, Le Bas JF, et al.: Prospective study of lacunar infarction using magnetic resonance imaging. Stroke. 1990, 21:546-554. 10.1161/01.str.21.4.546 